\title{
Mab-Zap: A Tool for Evaluating Antibody Efficacy for Use in an Immunotoxin
}

\author{
Matthew D. Kohls and Douglas A. Lappi \\ Advanced Targeting Systems, San Diego, CA, USA
}

BioTechniques 28:162-165 (January 2000)

\begin{abstract}
Immunotoxins, consisting of antibodies coupled to toxins, are extremely useful tools in the elimination of specific cell populations in vitro and in vivo for research and therapeutic applications. The antibody is used to target the toxin to a specific cell population, which is distinguished by its cell-surface antigen. Not all antibodies are suitable for creating an immunotoxin, and large numbers of antibodies may need to be screened. This is a time-consuming and expensive process if each potential candidate must be conjugated to the toxin and purified. A faster and more economical way to identify potential targeting antibodies is to use a second immunotoxin, an anti-IgG antibody that is coupled to the toxin. The second immunotoxin eliminates the need to couple every candidate antibody to the toxin because it can simply be added to cells in culture with the antibody of interest. Using this method, many antibodies can be screened quickly and efficiently for their ability to internalize.
\end{abstract}

\section{INTRODUCTION}

Immunotoxins are widely used to eliminate specific cell populations in vitro and in vivo for both basic research and pharmaceutical development. Immunotoxins are frequently cited in the neurosciences, where immunolesioning agents can be constructed from antibodies to specific cell types for the study of behavior (8). 192 IgG-SAP is the most specific and potent lesioning agent available for the cholinergic neurons of the basal forebrain (9), and reports of its use have appeared in over 100 publications. Immunotoxins may also have therapeutic applications: an anti CD-7-SAP immunotoxin is in preclinical development for the treatment of leukemia (4), for example.

The creation of an immunotoxin is a long and costly process. An antibody to the antigen of choice must be produced, and the performance of the antibody as part of an im- munotoxin must be evaluated. Desirable traits of an immunotoxin antibody include high specificity and rapid internalization. The choice of the correct antibody is crucial to the performance of an immunotoxin because a well-chosen antibody allows the complete elimination of a specific cell population with no nonspecific killing. If the antibody is to be conjugated to the toxin, both the unconjugated antibody and the free toxin must be purified away from the conjugate. Screening large numbers of antibodies for immunotoxin capabilities in this manner would be prohibitively expensive in both cost and time. The ability to perform a primary screen before conjugation and purification is a great advantage in the creation of an immunotoxin. Weltman et al. reported on a ricin-based second immunotoxin for screening monoclonal antibodies to tumor associated antigens (7).

Advanced Targeting Systems has created a second immunotoxin that is a useful tool for screening antibodies as potential immunotoxins. Called Mab-ZAP, this second immunotoxin is a goat anti-mouse polyclonal anti-IgG antibody that is conjugated to saporin, the most potent of the plant ribosome-inactivating proteins (5). Saporin induces cell death by apoptosis (1). The mechanism of action of Mab-ZAP is detailed in Figure 1. Use of a second immunotoxin eliminates the time-consuming and expensive step of conjugating each candidate antibody to the toxin: it can simply be added to cells in culture conditions together with the antibody of interest. Mab-ZAP allows a large number of antibodies to be screened quickly and efficiently or individual monoclonals to be evaluated for efficacy for use in an immunotoxin.

\section{MATERIALS AND METHODS}

These experiments are designed to demonstrate the specificity and function of Mab-ZAP and also show that Mab-ZAP will not be internalized easily by cells unless a primary anti- 
body is present. Mab-ZAP and $192 \mathrm{IgG}$ are administered to cells in culture both singly and together, and elimination of cells is measured. The results are also compared to the proven conjugate 192 IgG-SAP (Advanced Targeting Systems, San Diego, CA, USA).

\section{Cells}

C6 cells, a rat glioma cell line shown to express p75 (10), were obtained from ATCC (Manassas, VA, USA) and singlecell cloned for sensitivity to 192 IgG-SAP, creating cell line C6/9. Cells are maintained in F12K medium with $2 \mathrm{mM} \mathrm{L-}$ glutamine, $15 \%$ horse serum, $2.5 \%$ FBS, $1.5 \mathrm{~g} / \mathrm{L}$ sodium bicarbonate and penicillin-streptomycin.

\section{Antibodies and Immunotoxins}

Mab-ZAP is a goat anti-mouse $\operatorname{IgG}$ covalently linked to saporin, a ribosome-inactivating protein (RIP) from the seeds of the plant Saponaria officinalis $(3,6) .192 \mathrm{IgG}$ is a mouse monoclonal antibody to the rat low-affinity nerve growth factor receptor, also known as p75 (2). Xpress ${ }^{\mathrm{TM}}$ antibody, a

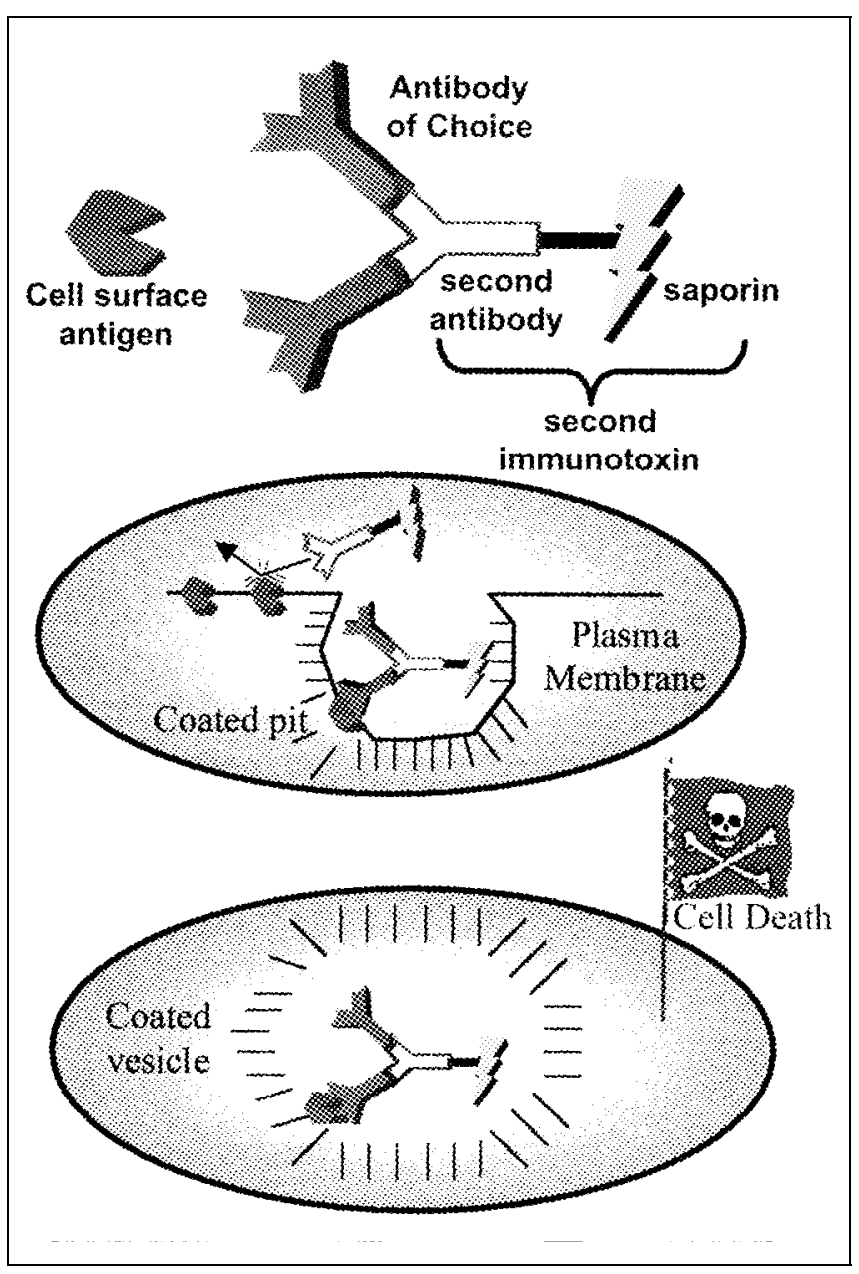

Figure 1. Schematic representation of Mab-ZAP design and function. (A) Mab-ZAP is represented as a second antibody coupled to the ribosome-inactivating protein saporin. Saporin is represented as a lightning bolt. The candidate antibody for an immunotoxin is represented by the antibody of choice. (B) The Mab-ZAP-antibody complex binds the cell-surface antigen and is internalized, but Mab-ZAP alone cannot enter the cell. (C) Once internalized, saporin inactivates the ribosomes, protein synthesis ceases and cell death occurs. mouse monoclonal antibody to an $\mathrm{N}$-terminal tag used in protein expression in the Xpress system was a gift from M. Bergseid (Invitrogen, Carlsbad, CA, USA).

\section{Cytotoxicity Assay}

We prepared 96-well microplates (Corning, Corning, NY, USA) by plating C6/9 cells at 2500 cells $/ 90 \mu \mathrm{L} /$ well. The plates are incubated $16 \mathrm{~h}$ at $37^{\circ} \mathrm{C}$ in the presence of $5 \% \mathrm{CO}_{2}$. The medium used is F12K that contains $2 \mathrm{mM}$ L-glutamine, $15 \%$ horse serum, $2.5 \%$ FBS, $1.5 \mathrm{~g} / \mathrm{L}$ sodium bicarbonate and penicillin-streptomycin.

Antibodies and Mab-ZAP are added in a volume of $10 \mu \mathrm{L}$, bringing the well volume to $100 \mu \mathrm{L}$. The plates are incubated $96 \mathrm{~h}$ at $37^{\circ} \mathrm{C}$ in the presence of $5 \% \mathrm{CO}_{2}$. For each plate, $75 \mu \mathrm{L}$ phenazine methosulfate $(0.92 \mathrm{mg} / \mathrm{mL}$ in Dulbecco's PBS $)$ are added to $1.5 \mathrm{~mL}$ (3-(4,5-dimethylthiazol-2-yl)-5-(3-carboxymet hoxyphenyl)-2-(4-sulfophenyl)-2H-tetrazolium, inner salt (MTS, $2 \mathrm{mg} / \mathrm{mL}$ in Dulbecco's PBS [both from Promega, Madison, WI, USA]), and $20 \mu \mathrm{L}$ are added to each well. The plates are incubated $1 \mathrm{~h}$ at $37^{\circ} \mathrm{C}$ in the presence of $5 \% \mathrm{CO}_{2}$.

The plates are read at $492 \mathrm{~nm}$ in a Spectra Max $340^{\circledR}$ and data analyzed using SOFTmax PRO 2.2.1 ${ }^{\circledR}$ (both from Molecular Devices, Sunnyvale, CA, USA) and GraphPad Prism ${ }^{\mathrm{TM}}$ (GraphPad, San Diego, CA, USA). A 4-parameter curve is generated using concentration and percent of control cells surviving, and the concentration of primary antibody at which the antibody + Mab-ZAP complex eliminates fifty percent of the cells $\left(E_{50}\right)$ is calculated from that curve.

\section{RESULTS}

First, a competitive assay demonstrates that the ability of Mab-ZAP in conjunction with $192 \mathrm{IgG}$ to eliminate C6/9 cells is comparable to 192 IgG-SAP. To avoid 192 IgG binding to $\mathrm{p} 75$ positive cells and internalizing before complexing, Mab-ZAP is always added to the wells first. Another alternative is to preincubate Mab-ZAP and $192 \mathrm{IgG}$ together before adding them to the wells. Sequential addition was chosen because it is much more efficient than preincubation for screening large numbers of primary antibodies. As seen in Figure 2, although the $\mathrm{ED}_{50}$ s listed in the table for Mab-ZAP + $192 \mathrm{IgG}$ are quite similar for the three concentrations of Mab-ZAP assayed, the curve generated by $50 \mathrm{ng} /$ well most closely approximates that generated by $192 \mathrm{IgG}-\mathrm{SAP}$. The $\mathrm{ED}_{50} \mathrm{~s}$ in Figure 2 also show that Mab-ZAP + $192 \mathrm{IgG}$ is three to fourfold less effective than the directly conjugated 192 IgG-SAP.

The curve generated with $10 \mathrm{ng} /$ well Mab-ZAP demonstrates that the elimination effect is diluted out by excess levels of free primary antibody (Figure 2). At low concentrations of Mab-ZAP and higher concentrations of $192 \mathrm{IgG}$, not all the $192 \mathrm{IgG}$ that has complexed with Mab-ZAP is internalized because uncomplexed $192 \mathrm{IgG}$ competes for the same sites on the C6/9 cells. For example, when $192 \mathrm{IgG}$ is at $10 \mathrm{nM}$ and Mab-ZAP is at $10 \mathrm{ng} / \mathrm{well}$, there is approximately a 210-fold excess of free 192 IgG over complexed Mab-ZAP + 192 IgG.

By itself, Mab-ZAP is not internalized at working concentrations. This fact is significant because no activation is necessary for the Mab-ZAP molecule to stop protein synthesis, only internalization so that the RIP (saporin) has access to the cellular ribosomes. As shown in Figure 3, significant cell 
death occurs only above $0.25 \mu \mathrm{g} /$ well of Mab-ZAP. Cell death is caused by bulk phase endocytosis, which would include Mab-ZAP. As the concentration of Mab-ZAP approaches 250 ng/well, the number of cells returns to $100 \%$ of control. In the absence of a primary antibody, Mab-ZAP is only internalized at high concentrations above $2.5 \mu \mathrm{g} / \mathrm{mL}$.

The internalization of Mab-ZAP is mediated by $192 \mathrm{IgG}$. The addition of Xpress antibody demonstrates that the elimination of cells by Mab-ZAP + $192 \mathrm{IgG}$ is diminished by competing the $192 \mathrm{IgG}$ away from Mab-ZAP with an antibody lacking a cell-surface antigen. (The product binds the mouse monoclonal Xpress antibody, but the Xpress antibody has no cell-surface antigen on C6/9 cells. Therefore, the Mab-ZAP + Xpress complex does not bind the cells and become internalized.) Figure 4 shows that the Xpress antibody does compete away Mab-ZAP from 192 IgG; at 1000 ng/well of Xpress antibody, the cell population returns to $78 \%$ of control. This re-

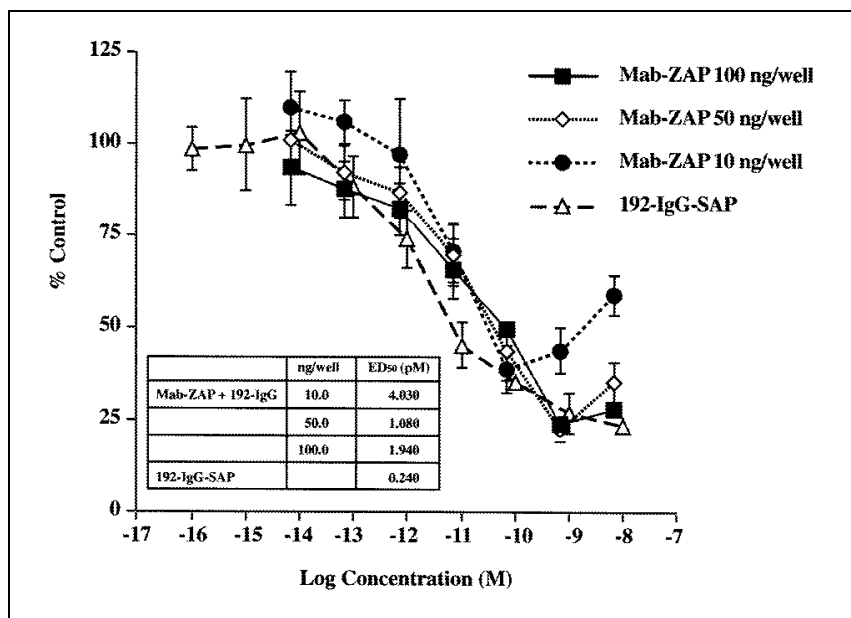

Figure 2. Assay of varying concentrations of Mab-ZAP with a dilution curve of 192 IgG. C6/9 cells are plated as previously described, then 10, 50 or $100 \mathrm{ng} /$ well of Mab-ZAP are added, followed by a dilution curve of 192 $\mathrm{IgG}$ from $10 \mathrm{nM}$ to $0.1 \mathrm{fM}$. The concentration of $192 \mathrm{IgG}$ is plotted against the percent control of treated cells. $192 \mathrm{IgG}-\mathrm{SAP}$ is added to a separate plate of $\mathrm{C} 6 / 9$ cells. The table compares the $\mathrm{ED}_{50} \mathrm{~S}$ of the varying concentrations of Mab-ZAP + 192 IgG to those of 192 IgG-SAP. A 4-parameter curve is generated for each set of data using Graphpad Prism. The program also calculates the $\mathrm{ED}_{50}$ for each data set from the curve.

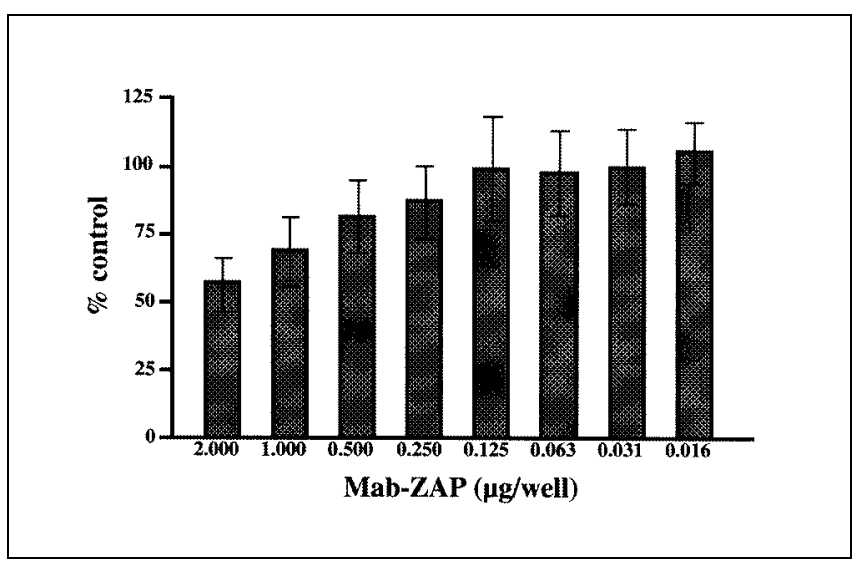

Figure 3. Mab-ZAP alone affects cell growth only above $0.25 \mu \mathrm{g} / \mathrm{well}$. C6/9 cells are plated as previously described and treated with a dilution curve of Mab-ZAP. Mab-ZAP is added to C6/9 cells in dilutions from $2 \mu \mathrm{g} / \mathrm{well}$ down to $0.016 \mu \mathrm{g} /$ well. The concentration of Mab-ZAP is plotted against the percent control of treated cells. sult is compared to $100 \mathrm{pM} 192 \mathrm{IgG}+50 \mathrm{ng} /$ well Mab-ZAP without Xpress antibody, which eliminates $>50 \%$ of the cell population, as shown in Figure 2.

The final step is to demonstrate the effect of varying the Mab-ZAP concentration in the presence of a constant concentration of 192 IgG. Figure 5 shows the effect when Mab-ZAP is diluted out against several concentrations of $192 \mathrm{IgG}$. As the Mab-ZAP concentration reaches $1 \mathrm{ng} /$ well, surviving cells approach $100 \%$. These data reinforce the data from Figure 2; for C6/9 cells, the most effective Mab-ZAP concentration is from 50-100 ng/well. A stoichiometric effect is also seen: as the number of 192 IgG molecules increases relative to MabZAP molecules, fewer cells are eliminated. Increased levels of free 192 IgG cause the ratio of Mab-ZAP + 192 IgG complexes to free $192 \mathrm{IgG}$ to decrease. More free $192 \mathrm{IgG}$ and fewer 192 IgG + Mab-ZAP complexes bind p75 and are internalized. Figure 5 illustrates the elimination of fewer cells with $1 \mathrm{nM} 192 \mathrm{IgG}$ than with $10 \mathrm{pM} 192 \mathrm{IgG}$ between 0.39 and 25 ng/well of Mab-ZAP.

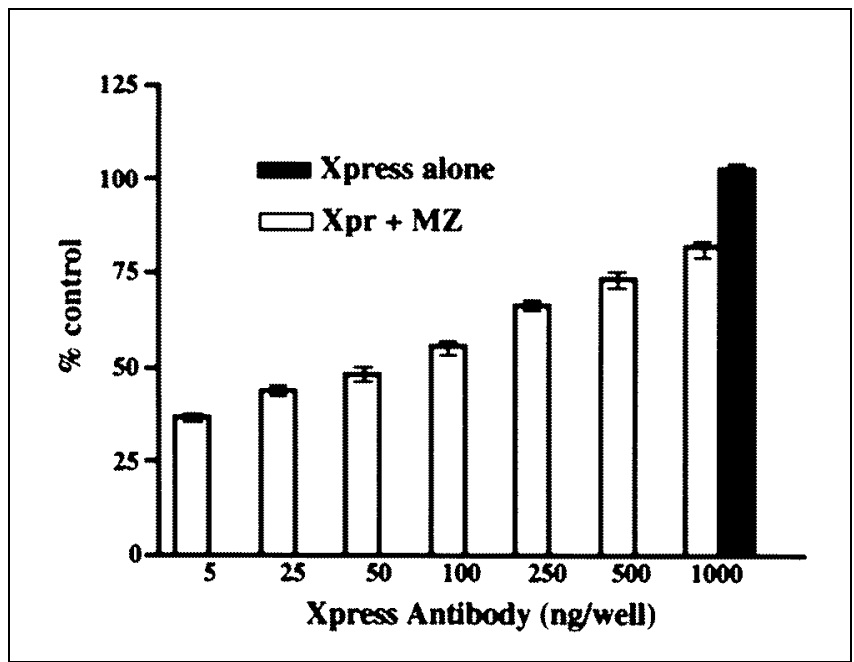

Figure 4. 192 IgG is competed away from Mab-ZAP by Xpress antibody. C6/9 cells are plated as previously described. Xpress antibody is added to the cells from 5-3000 ng/well. $192 \mathrm{IgG}$ is added to a final concentration of $100 \mathrm{pM}$ in each well, then Mab-ZAP is added to each well at $50 \mathrm{ng} / \mathrm{well}$. The amount of Xpress antibody is plotted against the percent control of treated cells.

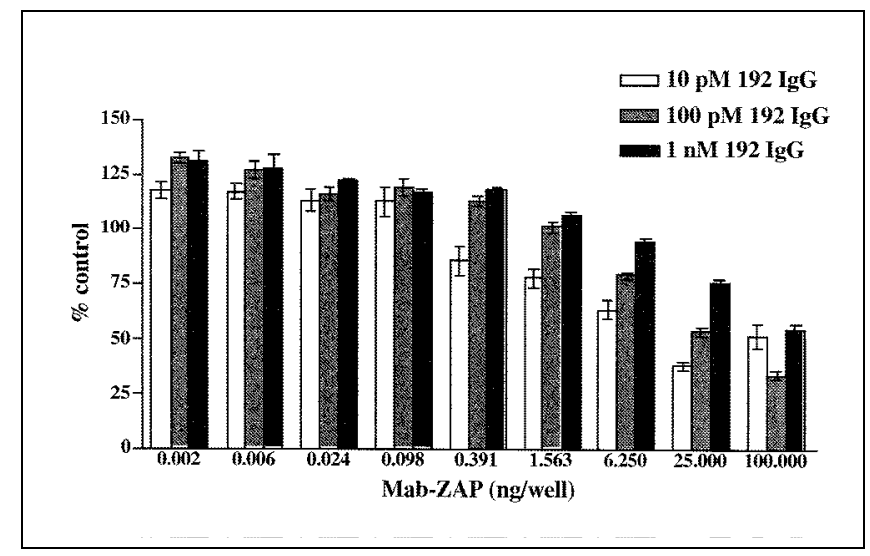

Figure 5. C6/9 cells treated with a dilution curve of Mab-ZAP and a constant concentration of 192 IgG give a dose-dependent response. MabZAP is added to wells in a curve from $100 \mathrm{ng} /$ well to $2 \mathrm{pg} / \mathrm{well}$. Wells are also treated with $1 \mathrm{nM}, 100 \mathrm{pM}$ or $10 \mathrm{pM} 192 \mathrm{IgG}$. Mab-ZAP (ng/well) is plotted against the percent control of treated cells. 


\section{DISCUSSION}

The usefulness of immunotoxins as research reagents and therapeutics is widely recognized, but efficient use of this technology requires an effective screening process. In these experiments, the effectiveness of the second immunotoxin, MabZAP, as a valuable tool for screening is demonstrated. A second immunotoxin demonstrates a candidate antibody's binding and internalization characteristics. It also facilitates narrowing down the number of antibody candidates for immunotoxins, which allows a concentration of time and effort on those antibodies that have the characteristics necessary to make an effective immunotoxin: specificity and internalization.

\section{ACKNOWLEDGMENTS}

The authors thank Denise Higgins for helpful discussions and manuscript review.

\section{REFERENCES}

1.Bergamaschi, G., V. Perfetti, L. Tonon, A. Novella, C. Lucotti, M. Danova, M.J. Glennie, G. Merlini and M. Cazzola. 1996. Saporin, a ribosome-inactivating protein used to prepare immunotoxins, induces cell death via apoptosis. Br. J. Haematol 93:789-794.

2.Chandler, C.E., L.M. Parsons, M. Hosang and E.M. Shooter. 1984. A monoclonal antibody modulates the interaction of nerve growth factor with PC12 cells. J. Biol. Chem. 259:6882-6889.

3.Lappi, D.A., F.S. Esch, L. Barbieri, F. Stirpe and M. Soria. 1985. Char- acterization of a Saponaria officinalis seed ribosome-inactivating protein: immunoreactivity and sequence homologies. Biochem. Biophys. Res. Commun. 129:934-942.

4.Morland, B.J., J. Barley, D. Boehm, S.U. Flavell, N. Ghaleb, J.A. Kohler, K. Okayama, B. Wilkins and D.J. Flavell. 1994. Effectiveness of HB2 (anti-CD7) - saporin immunotoxin in an in vivo model of human $\mathrm{T}$-cell leukaemia developed in severe combined immunodeficient mice. Br. J. Cancer 69:279-285.

5.Stirpe, F., L. Barbieri, M.G. Battelli, M. Soria and D.A. Lappi. 1992. Ribosome-inactivating proteins from plants: present status and future prospects. Biotechnology 10:405-412.

6.Stirpe F., A. Gasper-Campani, L. Barbieri, A. Falasca, A. Abbondanza and W.A. Stevens. 1983. Ribosome-inactivating proteins from the seeds of Saponaria officinalis L. (soapwort) of Agrostemma githago L. (corn cockle) and of Asparagus officinalis (asparagus) and from the latex of Hura crepitans L. (sandbox tree). Biochem. J. 216:617-625.

7.Weltman, J.K., P. Pedroso, S.A. Johnson, D. Davignon, L.D. Fast and L.A. Leone. 1987. Rapid screening with indirect immunotoxin for monoclonal antibodies against human small cell lung cancer. Cancer Res. 47:5552-5556.

8.Wenk, G.L. 1997. The nucleus basalis magnocellularis cholinergic system: one hundred years of progress. Neurobiol. Learn. Mem. 67:85-95.

9.Wiley, R.G., T.N. Oeltmann and D.A. Lappi. 1991. Immunolesioning: selective destruction of neurons using immunotoxin to rat NGF receptor. Brain Res. 562:149-153.

10.Zanellato, A., L. Facci, L. Petrelli, R. Dal Toso and S.D. Skaper. 1994. Characterization and growth-dependent regulation of the nerve growth factor receptor gp140trk in rat C6 glioma cells. Brain Res. Mol. Brain Res. 23:299-309.

Address correspondence to Dr. Douglas A. Lappi, Advanced Targeting Systems, 11175-A Flintkote Avenue, San Diego, CA 92121 USA. Internet: targeting@atsbio.com 